\title{
ICT Based Education for Literacy in India: Vision Beyond 2015
}

\author{
Syed Nitas Iftekhar and Hyeon Jihye
}

\begin{abstract}
Proportion of adult illiterates has improved in many countries over the last decade. Yet, the number of adult illiterates in India has remained the highest at 287 million since 1990 to 2010 because of the population growth. India constitutes of more than one-thirds of the world's adult illiterates which needs serious attention from the government. Defining literacy has been a debate in India, as in many developing nations. Literacy should be recognised as a continuum and as the laying stone of lifelong learning. Adaptation of skills and Information Communication Technologies (ICTs) with functional literacy skills as base for lifelong learning has to be a core element of the basic education agenda in India post 2015 . The goal, targets and indicators for literacy have to be defined in a way that makes sense in relation to an overarching human capability agenda. Furthermore, multiple literacy skill levels need to be recognized. In India there is need to expand formal and non-formal adult education with the concept of life-long learning using ICT. It is suggested in the paper, how India can develop a strong and effective ICT based education system to impart literacy.
\end{abstract}

Index Terms-Literacy, ICT based education, life-long learning, India, information communication technology.

\section{INTRODUCTION}

Literacy, the foundation of all education and lifelong learning, is an essential component of the right to education. However, according to the latest Education for All (EFA) Global Monitoring Report [1], adult literacy around the globe remains an elusive goal.

The Education for All agenda set an international target of achieving a 50 per cent improvement in levels of adult literacy by 2015 . India set a national target of target of reaching 80.5 per cent adult literacy rate by 2015 . Despite such national and international targets and continuous efforts towards the same, there is still an alarming number of adult illiterates.

The global adult illiteracy rate fell from 24 per cent in 1990 to 18 per cent in 2000 and further to $16 \%$ in 2011 . However, the number of illiterate adults remains stubbornly high at 774 million, a fall of $12 \%$ since 1990 but just $1 \%$ since 2000 . India's current trend literacy trend shows only 71.4 per cent adults and about 60 per cent female adults will be literate by 2015 [1].

It is irrefutable, that the need of the hour is to literate adults across the globe. As the year 2015 approaches it is becoming

Manuscript received August 16, 2014; revised December 1, 2014.

Syed Nitas Iftekhar is with Centre of Excellence in Public Policy and Governance at Indian Institute of Management Kashipur, India (e-mail: nitas711@gmail.com).

Hyeon Jihye is with the Institute of International and Comparative Education, Beijing Normal University and UNESCO Beijing, China (e-mail: sophiehyeon@gmail.com). increasingly important to understand better how the contribution of ICT can play an important role in the post-EFA agenda to impart literacy and life-long learning.

In regard with this, the route which India has been working towards education for literacy after post EFA-2015 should be looked at closely, to utilize the country's strength in ICTs to impart literacy. In this study, we shall elaborate how India can optimally use ICTs in Education to impart youth and adult literacy beyond 2015 .

\section{BACKGROUND}

\section{A. Global Contexts}

In the past decades of the 21 st century, there has been considerable international attention given to the role that ICT can play in economic, social, and educational change. It has been asserted that ICT in education has become an engine of growth for the global economy. ICT in education has the potential to contribute significantly to sustainable economic development, to enhance public welfare, to strengthen democracy, to increase transparency in governance, to nourish cultural diversity, and to foster international peace and stability through educating the children, youth and adults [1]. It is necessary that the use of ICT in education is central to the post-2015 EFA agenda or any International Agenda because of the severe needs to develop human resources capable of responding to the demands of the information age and to nurture ICT literacy and skills through education, training, and lifelong learning.

ICT has played an instrumental role towards achieving Education for All (EFA) and Millennium Development Goals (MDGs) and shall continue do the same in the post 2015 international agendas if given proper attention and policy [1].

\section{B. ICT in Education - Case of India}

Rapid technological advancement and introduction of ICT in education have benefitted India greatly, especially at primary and secondary education levels. Various modes of e-learning, use of ICTs in classrooms and Distance Education programs have significantly improved the education access and achievement in India.

India has witnessed a few milestones to promote ICT driven education. Imparting literacy to the adult masses has been a part of the mandate for the government of India for a long time. The National Literacy Mission (NLM), launched in 1988, was based on the 1986 National Policy on Education after which many literacy initiatives followed. India launched a dedicated satellite EDUSAT in 2004 with the purpose to bring both quantitative and qualitative revolution in education and help in e-learning and self education. Recently, the Indian 
Government proposed use of ICTs in education in its Eleventh five year plan (2007-2012) and set up a National Mission in Education (NME) through ICT [2]. A number of ICT related projects have been implemented by NME-ICT for development of e-learning education environment. Some of the major projects are eGyanKosh, Flexilearn, NPTEL, CEC, Institute of Lifelong Learning (ILLL), e-PG Pathshala [3].

The use of new learning technologies contributing greatly in classrooms across the country has opened up significant opportunities for informal and continuing literacy learning in adult and youth basic education programmes. The use of ICT in Education has been popular because of the various advantages offered to the Indian learners; it has provided improved learner support, widened the access to resources, and given the learner to learn anywhere, any time.

Yet despite these advantages, use of ICT in Education has been quite limited to only some privileged groups, particularly those residing in urban areas and who have the financial means to afford such education. A high drop-out rate amongst the young adolescents also leads to the result that they are unable to engage and get the benefit from ICTs in education effectively.

Low adult and youth literacy rates coupled with the socio-economic changes taking place within and outside India due to globalization, liberalization of the economy and the tremendous expansion of ICT have necessitated a review of adult education policy and its reformulation.

As India approaches the 2015 EFA deadline, it is projected that it shall achieve goal 2, yet significantly fall back in terms of adult and youth literacy [1]. This calls for reform in literacy education in India. India does not have a national plan for ICT in education as it is the responsibility of individual states to develop plans to carry out policy set at the federal level [4].

\section{Challenges in ICT Based Education in India}

Some main challenges India has faced in the critical domain of using ICTs in education for literacy, are briefly described below:

Inclusion for use of ICT. It has been a challenge to provide equal opportunities for the economically and demographically disadvantaged populations [5]. Such populations have found it hard to afford and ensure continuous access to ICT devices for learning and skill development.

Internal Divide. Beyond sub-regional differences, the internal digital divide of India has also increased significantly as urban areas quickly adopt and further their use of ICTs while it remains out of reach for rural and remote regions. Moreover, as technological advancements take place rapidly, there is a risk that advanced technological requirements may lead to the further exclusion of large numbers of people from sharing the advantages of the new global communication channels [6].

Struggle to cope with ICT developments. Innovations in technology and new products are introduced in the global marketplace at a much faster pace than most educational systems are able to use them effectively. This issue of policy timing is important and necessitates that policy ensures institutions are on track as ICTs improve and develop at a rapid pace [7].
Traditional Mindsets. Majority of adult illiterates especially those who have never used ICTs, are hesitant to use and immerse themselves in learning from ICTs. They prefer the traditional ways of education and don't deem ICTs to be useful for them [8]. This scenario mandates a necessity for creating awareness and sensitizing youth and adults towards the uses of ICTs in education.

Lack of resources in backward areas. There is an evident lack of resources such as power electricity and facilitators especially in backward and rural areas to use ICT in imparting literacy which prove to be a significant obstacle to integration of ICT in education in India. Moreover, there is also a scarcity of teachers trained in the use of ICT for literacy education.

Weak Monitoring and Evaluation Standards. Another problem in this area is the lack of a common set of indicators to monitor and evaluate use of ICTs in education. And, where data has been collected, it is often quantitative data related to infrastructure (for example, number of computers) rather than data that can help policymakers gauge the impact of ICT interventions on student learning.

Lack of National Policy. India also has not formulated any policy with regards to the use of ICT to impart adult literacy. The lack of policy regulation doesn't give the issue much attention and financial support. Most such projects using ICTs to impart literacy are small scale, and carried out by NGOs in collaboration with other partners and lacks support from the government. A national policy on ICTs for literacy would prove to be a strong laying foundation for further developments post 2015.

Despite these challenges, the use of new learning technologies has contributed to opening up opportunities for informal and continuing literacy learning for adult and youth education programmes in India. ICTs in education can further facilitate skills development, encourage use of learner-generated materials, stimulate awareness-raising and learner motivation, support and train literacy workers, contribute to education for sustainable development, facilitate the distribution and updating of materials and information to resource centres and gather feedback.

\section{Types of ICT Assisted Instruction for Youth and Adults in India}

In the current era of technology, ICTs in India should be seen as a platform to overcome the negatives of traditional education and make learning more efficient for the adult learners, imparting literacy to the illiterates at a faster pace than in the past. It is also recognized that learners who use ICT for basic skills double the value of their study time acquiring two sets of skills at the same time so it is deemed to be very beneficial while imparting literacy [9]. Meeting these demands may take many forms - from distance learning on a radio or TV, to newer devices like the widespread mobile phone which can be better classified under types of ICT assisted instructions. It refers to teaching methods or models of instruction delivery that employ ICT in supporting, enhancing and enabling course content delivery. It may include any, all or different combinations of the following:

1) Radio-assisted instruction. It can be in the form of Radio broadcast education, where an audio lecture or lesson is given, with printed material to be used by learners 
supporting the audio. Another form is interactive radio instruction which requires that learners give feedback and answers to questions and exercises through verbal responses to radio programme contributors, while the programme is on air. Three pilot projects in India titled 'Khilti Kaliyan,' 'PREAL' and 'Chauraha' attempted to use television (discussed below) and radio for teaching literacy to adults, particularly adult women.

2) Television-assisted instruction. It is equipped the additional benefit of video along with audio. It helps to bring learning concepts through clips, animations, simulations, visual effects and dramatisation. Traditional television instruction has been a benefit in many parts of India but it has been disadvantageous in terms of lack of flexibility and limited interactivity [10] as it shares the same rigid scheduling as radio broadcast education.

3) Computer-assisted instruction. It is an interactive method unlike previous to learning methods. In this, a computer is used by teachers and learners to present instructional material, to perform tasks for learning and to help in accessing additional pedagogical material.

4) Internet-assisted instruction. It refers to an interactive learning method using content from the World Wide Web for pedagogical purposes. Learners explore information from all these online resources and construct their own knowledge for different purposes [11].

Radio and TV have been providing educational programmes for the youth and adults in India for many years. New technologies, including satellite broadcasting and multi-channel learning, have potential to immensely increase access to education for youth and adults. Presently, the internet is not widely available in most rural areas, but latest Internet Technologies and Mobile Internet centers hold promise for effectively connecting teachers, learners, and communities. There also various other ways of ICT assisted type instruction [11], which can be a great help in imparting literacy. New media has enormous potential for creating learning spaces, such as interactive websites, chat-rooms, web-based courses and online libraries.

\section{ICT BASED EDUCATION}

\section{A. Present and Beyond 2015}

Non-Governmental and International organizations such as UNESCO have shown concern to enable all people around the world to make use of the huge potential of ICT for learning and self-empowerment. Furthermore, it is accepted that universal literacy is fundamental to social and economic progress. As the case of India stands, there are huge differences in levels of literacy according to different states, levels of income, family background and so on. With supportive policies, strategic planning and monitoring, ICTs hold out the promise of facilitating greater inclusion of such groups [7]. The focus of imparting literacy using ICTs beyond 2015 should be on the marginalized sections of the society. Such sections have been enumerated below:

1) Rural inhabitants

2) Poverty stricken families

\section{3) Young girls and women}

4) Ethnic, religious and linguistic minorities

For improving literacy using ICTs, the key would be to focus on the dissemination of ICT education in the areas and population that has been neglected so far.

With fast developments in technology perceptions of a literate person are also changing, which necessitates that those who are marginalized are also kept abreast with the new developments, so that that they maintain the levels of literacy as per rising standards. As use of ICTs grows, it would be mandatory for people; particularly women who are denied opportunities conventionally, to go beyond basic literacy to develop digital literacy that would be necessary to utilize the new technologies effectively and productively for their own empowerment to be not left behind [12].

\section{B. Way Forward - Key Focus Areas}

\section{1) ICT in rural areas}

About 68 percent of the population in India resides in rural areas (about 845 Million people), comprising of a large portion of the adult illiterates in the country. Moreover, regional differences in adult literacy rates are also quite significant within India. The national literacy rate in 2008 was 66 percent with lowest literacy in the state of Bihar (48 percent) and highest being from the state of Mizoram (95 percent). The rural-urban differentials of adult illiterates are higher for females than for males. For instance, in the year 2008, national average for female adult literacy was at 54.9 per cent. Bihar and Rajasthan both large states- by area and by population, recorded female adult literacy of just 34.6 and 35.2 percent respectively [13]. On the other hand, the states of Kerela and Mizoram recorded female adult literacy rates of more than 90 percent for the same year.

Use of ICTs to impart adult education in areas with low literacy will not only increase literacy, but it will increase economic productivity eliminating poverty, raise awareness towards health issues benefiting especially women and children and improving the overall standards of living.

To bolster Adult Education and Skill Development in rural areas, Government of India introduced two new schemes, namely Saakshar Bharat (Literate India) and Scheme for Support to Voluntary Agencies for Adult Education and Skill Development during the Eleventh Five-Year Plan. Furthermore recognizing the need to address the female illiterates, a new National Mission for Female Literacy (Saakshar Bharat) has been launched. Such programmes have been successful to an extent, and can further provide greater results by the inclusion of ICT in education for rural areas. In today's knowledge driven societies lack of literacy is more than ever synonymous with exclusion and marginalization and it becomes necessary that adults in rural areas are not excluded.

ICT based education will improve efficient delivery of resources to the poor, bring markets within reach of rural communities, to improve government services, and to transfer knowledge needy to meet any national goals [14].

\section{2) ICT in non-formal education}

India has struggled in its own way and has begun to transform the adult education programmes so far dominated by literacy into multi-faceted learning opportunities for youth 
and adults. India faces one of the biggest challenges as 287 million illiterates are from India and out of the total adult illiterates, almost two-thirds of this number is women which elicit social and gender disparities. India has witnessed improvements in the percentage of adult literates, but the total number of literates has been stagnant due to the high population growth rate. The literacy movement that was launched in India in the 1990s and later has few parallels elsewhere in the world in respect of its scale, scope, implementation structure and innovations including its "Mission" approach to overcome bureaucratic constraints. To follow such an approach further after 2015 it will be crucial for India to introduce ICT in non-formal adult education.

In India, non-formal education may cover educational programmes to impart adult literacy, basic education for out-of-school youth, life skills, work skills and general knowledge.

ICT has proven effective delivery mechanisms to improve the accessibility of non-formal educational programmes. They are usually delivered through Community Multimedia Centres (CMCs), Community Learning Centres (CLCs), or Telecentres. Meanwhile, ICT literacy and ICT application skills have become important emerging life-skill and work-skill contents of non-formal educational programmes to help out-of-school youth and adults find work and become empowered in the information society.

ICT based non-formal education activities will provide out-of-school adolescents and youth access to structured learning, reinforce their self-esteem and help them find ways to contribute to their communities. It is important to address the youth so that they don't translate into adult illiterates in the future. In some cases, ICT based non-formal education may serve as a bridge to help out-of-school adolescents improve their academic skills to the point where they can re-enter the formal school system. Similarly, adults in the country will also gain from such programmes by gaining necessary skills through ICT to get employment or contribute to their professional development.

\section{3) ICT in life-long learning}

Technology can make lifelong learning a reality [15]. At this crucial juncture around the year 2015, EFAs and MDGs come to a deadline, it is necessary for India to go beyond conventional definition of learning and re-think learning. India needs to cultivate lifelong learning to build a learning society that should enable all youth and adults to participate in lifelong learning programs related to work, citizenship and personal fulfilment. Non-formal education should be given equal importance such as Community Learning Centres etc. to help eradicate a major hurdle of adult functional literacy [16].

The National Policy on Education in India, 1986 considered lifelong education as the cherished goal of the educational process which presupposes universal literacy, provision of opportunities for youth, housewives, agricultural and industrial workers and professionals to continue the education of their choice at the pace suited to them [11]. Such foresight in those days, mandates that it is followed up with concrete actions in the form of ICT based life-long learning opportunities for the adults.

India should capitalize on its philosophy and tradition of learning throughout life. It was only in 2007 that the Government of India put forward the idea of expanding the scope of the Continuing Education Programmes by developing it as Lifelong Education and Awareness Program (LEAP) [17].

The practice of lifelong learning itself has been facilitated by the demonstrable fact of thousands (now millions worldwide) of adults studying beyond school age using a range of media, and pursuing both occupational and personal goals [18]. Confronted with the massive problems of illiteracy and poverty in India, there is a severe need for ICT based life-long learning. Current problem faced by the country is the vision required to frame lifelong learning policy, develop programs and institutional infrastructure based on ICTs.

In future users of lifelong learning services to be offered by educational institutions may be expected to be mostly adults with different levels of background knowledge and different levels of ICT skills. Therefore, it is crucial at this stage that life-long learning platforms are built on friendly, easy to use and robust technology. On the other hand, the didactics will have to be designed in a way that the learning process is motivating for the learner, so that it supports the information age generation (constructivistic learning) and that it improves transfer of acquired knowledge in a learning process into a practice. New technologies like mobile-learning (using tablets, personal digital assistants, mobile phones) will aid to life-long learning programs by making the learning possible practically anywhere and anytime [19].

It may be argued that the Indian interest in lifelong learning till date has been greatly influenced by the global discourse on lifelong learning and its advocacy by the transnational organizations like the UNESCO and the European Commission. These two organizations have not only played a key role in publicizing the concept of lifelong learning in India, but also in orienting the government officials and academic community towards lifelong learning. Post 2015 India should show their commitment to using ICT based life-long learning in the form of policy for eradicating adult literacy. India has taken a positive step as the 12th Five Year Plan (2012-2017) sub-committee on Adult Education has emphasized the need for developing a comprehensive policy to guide the systematic promotion of adult and lifelong learning and the creation of structures and mechanisms for recognition, validation, accreditation and certification of prior learning [20]; it is expected that lifelong learning will soon become a reality and an important strand of India's education policy and the use of ICTs will play a critical role for the same.

\section{4) Sustainable development}

Globally there is also a pressing need for Education for Sustainable Development (ESD) and many countries are practising ESD and strategizing to develop ESD beyond 2015 as the United Nations Decade of Education for Sustainable Development (DESD, 2005-14) comes to an end. ICTs are a very efficient and effective way to imparting education for sustainable development along with literacy. It will allow the youth and adults of India to acquire the knowledge, skills, attitudes and values necessary to shape a sustainable 
future. Education for Sustainable Development means including key sustainable development issues into teaching and learning; for example, climate change, disaster risk reduction, biodiversity, poverty reduction, and sustainable consumption and ICTs should be at the crux of ESD post 2015. It will help sustain people, communities and ecosystems in India and advocate the message of learning to live together. It is utmost important to re-orient education in this direction. Education for sustainable development requires far-reaching changes in the way education is being practised today.

\section{Suggestions Post 2015Development}

Taking into consideration the benefits of a literate population, India should consider taking a bold step towards educating the illiterate youth and adults. Some recommended strategies are suggested for the same:

\section{1) Formulate a clear national policy}

The process of developing the policy framework of ICT based adult education has been rather slow in India It is recommended that since the knowledge base of ICT based adult education or lifelong learning in India continues to be weak, systematic efforts should be made to generate new knowledge through rigorous researches and scholarly publications. There is a need to formulate policy based on rigorous research that enables the integration of appropriate forms of ICT into literacy programmes with consideration to the different needs of adults within the country. In addition it is necessary to facilitate implementation of cross-cutting, integrated literacy programmes [21].

\section{2) Provide proper infrastructure}

ICT-based literacy programmes in India have suffered from inadequate infrastructure and technical support especially in rural areas. Policy makers should address the need of essential infrastructure requirements (electricity, internet connectivity, phone lines etc.) in needy areas.

\section{3) Proper monitoring and evaluation of projects}

As the latest Global Monitoring Report by UNESCO (2014) has suggested each post-2015 goal must be clear and measurable, with the aim of ensuring that no one is left behind. To achieve this, progress should be tracked by the achievements of the lowest performing groups, making sure the gap between them and the better-off is narrowing [16]. All literacy projects must have monitoring and evaluation mechanisms built into the structure to determine the progress. Keeping a track of data will also help policy makers understand the strengths and weaknesses of the programs. Relevant and useful data are vital in order to make decisions regarding improvements to the project. Data should also be maintained on a national level for international research and comparisons.

\section{4) Strengthen partnerships with stakeholders}

The success of ICT based literacy projects also depends on establishing strong partnerships and collaborations between stakeholders (Government, NGOs, International Organisations, Institutions etc.) to make the most of the strengths and assets of the stakeholders. India should evaluate appropriately, how public-private partnerships can be an effective and affordable way of bringing ICT expertise and experience into educational activities.

Coordination of efforts by the various institutions, ministries and organizations involved in the process of implementing ICT based education will ensure that there is no duplication and wastage of resources. It is important to also ensure that funding is secure and lasts throughout the project [21].

\section{5) Community participation}

Community participation in this process is vital, as experiences in many countries have shown that literacy projects are more useful and sustainable when communities support and commit to them [21]. The community should be sensitized about the benefits of ICT based education so to increase motivation of learners with a greater level of participation.

\section{DISCUSSION}

In order to effectively impart literacy using ICTs it is required that the post 2015 national approach be innovative and inclusive, learning and education strategies must recognize all places where learning takes place: at work, in the community, in the family, and in social and civic life. ICTs have tremendously broadened the opportunities for people to acquire information, interact, network, address issues of common concern, generate income and participate in society. The importance of local context and systematic capacity building is key. Furthermore, careful monitoring and evaluation, and coordination, is critical to success of ICTs in India which has not been a strong point thus far.

As educational achievements are shaped not only by the way education is organised but also by the socio-economic background of the learners, their socio-cultural environments, the changing skills and competences that are necessary for employment, education and training, self-development and participation in society non-formal learning, informal learning and adult learning are increasingly seen as crucial for the future of learning.

A concrete vision of "ICT and learning" is needed that takes into account the shifts and trends (e.g. globalisation, migration, demographics, technological progress) that are transforming the way people work, learn, enjoy themselves and make sense of their world. Preferably, this vision would be realised through a proactive strategy that envisages and anticipates future learning needs and requirements, rather than an adaptive strategy which simply reacts to new requirements as they arise [22].

In order to make successful use of ICT in enhancing the reach and quality of teaching and learning, policy makers need to be aware of how ICT can be of best value in their country's education system, and need to develop a supportive policy environment and framework at the national level for the integration of ICT into their education systems [23].

If ICTs are to become effective and integral tools to impart literacy in India, and if accountability is to be demonstrated to donors and stakeholders, monitoring and evaluation must be a priority area of focus. ICT based education imparting adult literacy can provide exciting and effective educational 
possibilities, ICT can connect with communities of learners who have been excluded by traditional education provision, and ICT involves a new and important set of skills, that is of value to adult learners.

\section{CONCLUSION}

It is expected that the challenges highlighted and suggestions presented in this paper will present cause for dialogue and future research to understand the situation of ICT based education in India and strategize ways to improve it. As explicated in previous sections, levels of literacy in India in the coming years will play a major role in national development and will have an impact on the world. Therefore, ICT based education beyond 2015 must be given greater priority in India as well as globally.

\section{REFERENCES}

[1] United Nations Educational, Scientific and Cultural Organization, "Teaching and learning: Achieving quality for all," EFA Global Monitoring Report, Paris: UNESCO, 2014.

[2] Ernest \& Young, "Higher education in India: Twelfth five year plan (2012-2017) and beyond," presented at FICCI Higher Education Summit 2012, Planning Commission Government of India, New Delhi, 2012.

[3] N. Gupta, "Cloud computing: New era in education," International Journal of Advanced Engineering Technology, vol. 5, no. 2, pp. 44-46, 2014.

[4] Government of India, "National policy on information and communication technology (ICT) in school education," New Delhi: Department of School Education and Literacy, Ministry of Human Resource Development, 2012.

[5] S. Desai and V. Kulkarni, "Changing educational inequalities in India in the context of affirmative action," Demography, vol. 45, no. 2, pp. 245-270, 2008.

[6] D. Archibugi and C. Pietrobelli, "The globalisation of technology and its implications for developing countries, windows of opportunity or further burden?" Technological Forecasting \& Social Change, vol. 70 pp. 861-883, 2003.

[7] M. Trucano, Knowledge Maps: ICT in Education, Washington, DC: infoDev/World Bank, 2005.

[8] D. A.Wagner and R. B. Kozma, New Technologies for Literacy and Adult Education: A Global Perspective, Paris: UNESCO, 2005.

[9] Department for Education and Employment, A Fresh Start: Improving Literacy and Numeracy, London: DfEE, 1999.

[10] World Bank, Information and Communication Technology for Education in India and South Asia (Volume 1) Extend Summary, Washington. D.C.: InfoDev/Price Water House Coopers, 2010.

[11] N. Patil, "Constructive e-learning: An outstanding way of lifelong learning," International Journal of Information and Education Technology, vol. 2, no. 6, 2012.

[12] United Nations Educational, Scientific and Cultural Organization, Participatory Adult Learning, Documentation and Information Networking (PALDIN), New Delhi: Jawaharlal Nehru University, 2007, pp. 187-191.

[13] Government of India, Education for All: Status and Trends, New Delhi National University of Educational Planning and Administration, 2012.

[14] World Bank, ICT and MDGs: A World Bank Perspective, Washington: World Bank, 2003.

[15] E. A. Regan, "Lifelong learning and performance: Linking academia and business," Office Systems Research Journal, vol. 16, no. 12, p. 43 , Springfield, 1998.
[16] N. I. Syed, "Learning from the past, strategizing for the future: EFA in India beyond 2015," BCES: Bulgarian Comparative Education Society, Sofia: BCES, 2014.

[17] S. Y. Shah, The Policy and Programmes of Lifelong Learning in India, 2011.

[18] J. S. Daniel, Mega-Universities and Knowledge Media: Technology Strategies for Higher Education, London: Kogan Page, 1996.

[19] D. Dinevski and P. Kokol, "ICT and lifelong learning," University of Maribor, Slomskov: University of Maribor, 2004.

[20] Government of India, Working Group Report on Elementary Education and Literacy- Twelfth Five Year Plan (2012-17), New Delhi: Ministry of Human Resource Development, 2011.

[21] United Nations Educational, Scientific and Cultural Organization, Using ICT to Develop Literacy, Bangkok: UNESCO, 2006.

[22] Y. Punie, D. Zinnbauer, and M. Cabrera, "A review of the impact of ICT on learning," European Commission Joint Research Centre, Institute for Prospective Technological Studies, 2006.

[23] United Nations Educational, Scientific and Cultural Organization, Technologies for Education: Achievements and Future Initiatives in the Asia-Pacific Region, Bangkok: UNESCO, 2005.

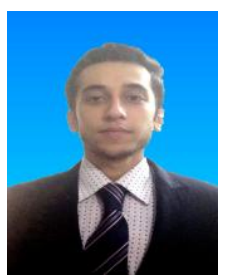

Syed Nitas Iftekhar was born and brought up in New Delhi, India after which he went to China for post graduate studies in the field of education. $\mathrm{He}$ completed his M.A. degree in comparative education and policy, Beijing Normal University, Beijing, China in 2014.

Since 2007, he has worked extensively at the grass-roots level in NGOs in India focusing on education, literacy and women empowerment. He has conducted research on various topics, as a research associate for UNESCO INRULED and UNESCO, Beijing Office. Currently, he is working at Indian Institute of Corporate Affairs (IICA), Ministry of Corporate Affairs, Government of India, New Delhi, India on Corporate Social Responsibility related activities. Currently, he is working at Centre of Excellence in Public Policy and Governance at Indian Institute of Management (IIM) in Kashipur, India which is a leading policy think tank dedicated to extensive and cutting-edge international research, teaching and capacity building on economic, social and political isssues.

Mr. Syed is also a member for Comparative International Education Society and Bulgarian Comparative Education Society. He had been awarded the Chinese Government FulBright Scholarship for his Masters Degree and Outstanding International Student award from Beijing Normal University. He has contributed to some important international publications such as China Ten Year EFA Report (UNICEF-UNESCO) and Skills Development for Rural Transformation (INRULED).

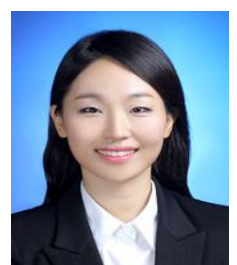

Hyeon Jihye was born in Seoul, Republic of Korea, and she got a bachelors' degree of English literature and language in Hanyang University in Seoul, Republic of Korea in 2007. Since she got awarded Korean Government Scholarship and Chinese Government Scholarship in 2013, she has been studying for a master's of international comparative education in Beijing Normal University in Beijing, China. Her major field of study is parent education, especially antenatal parent education for pregnancy and nurturing using ICTs. Her paper regarding this field won the grand prize in a research contest held by UN Global Compact in 2014; The title of the paper is Emerging Models for Technologically-enabled CSR: Antenatal Parent Education to Reduce Maternal and Infantile Mortality in Ghana.

She worked in the field of academic curriculum and educational planning \& management in Republic of Korea since 2004. Currently she has worked in UNESCO Beijing Cluster Office as a research associate. The UNESCO projects she has been involved are ICT in education in Democratic People's Republic of Korea, CCE (Climate Change Education) in Mongolia, TVET (Technical and Vocational Education and Training) for young migrant workers in China. 